\title{
A ESTERILIZAÇÃO FEMININA: ASPECTOS CONSTITUCIONAIS, LEGAIS E BIOÉTICOS
}

\author{
Clara Angélica Gonçalves Cavalcanti Dias ${ }^{1}$ \\ Renata Oliveira Lima ${ }^{2}$
}

\section{RESUMO}

No Brasil, apesar da esterilização ter sido autorizada na rede pública somente com o advento da Lei 9263/96, o procedimento cirúrgico ainda é, um dos métodos mais utilizados pelas mulheres para o controle de sua fecundidade nos países latino-americanos; e a esterilização compulsória é considerada ilegal. Tal tema ainda é muito contraditório, visto que, para alguns autores, fere alguns princípios balizadores do direito e promove uma série de discussões principalmente no tocante a violação do Princípio da Dignidade da Pessoa Humana que é visto como princípio maior da Constituição de 1988

Palavras-chave: Esterilização feminina. Filiação. Gravidez. Mulheres. Princípio da Dignidade da Pessoa Humana.

\section{FEMININE STERILIZATION AND STATE INTERFERENCE IN THE RIGHT TO PROCREATION}

\begin{abstract}
In Brazil, although sterilization has been authorised in the public network only with the advent of Law 9263/96, the surgical procedure is still one of the methods most used by women to control their fecundity in Latin American countries; and compulsory sterilization is considered illegal. This theme is still very Contradiótiro, since, for some authors, it injures some guiding principles of law and promotes a series of discussions mainly regarding the violation of the Principle of Dignity of the Human Person which is seen as the greater principle of 1988 Constitution.
\end{abstract}

Keywords: Female sterilization. Filiation. Pregnancy. Women. Principle of the Dignity of the Human Person.

\section{1-INTRODUÇÃO}

\footnotetext{
${ }^{1}$ Possui graduação em Direito pela Universidade Tiradentes- UNIT, Pós graduação lato-sensu em Direito pela Escola Paulista da Magistratura. Mestrado e Doutorado em Direito pela Pontifícia Universidade Católica de São Paulo- PUC/SP. Professora Efetiva de Direito Civil do Departamento de Direito da Universidade Federal de Sergipe. Advogada regularmente inscrita nos quadros da Ordem dos Advogados do Brasil. Pesquisadora na área de Direito Civil. Com endereço postal: Alameda Antônio de Pádua Araújo, 155. Apto 1201C. Bairro Jardins. Aracaju-SE. CEP 49027-400. Endereço Eletrônico: claragdias@gmail.com

2 Possui graduação em Direito pela Universidade Tiradentes- UNIT. Atualmente é mestranda pelo Programa de Pós Graduação em Direito da Universidade Federal de Sergipe. Advogada regularmente inscrita nos quadros da Ordem dos Advogados do Brasil. Pesquisadora na área de Direito Civil. Com endereço postal: Alameda Antônio de Pádua Araújo, 155. Apto 1201C. Bairro Jardins. Aracaju-SE. CEP 49027-400. Endereço Eletrônico: renatalima.advocacia@gmail.com
} 
As relações sociais encontram-se em constante adequação às mudanças globalmente ocorridas decorrentes dos avanços científicos e tecnológicos. Nesse contexto, o direito, enquanto produto sociocultural, necessita encontrar soluções para as novas e diversas questões que surgem, não somente como forma de promover pacificação social, mas também para que não se coloque em risco os direitos inerentes ao ser humano enquanto pessoa.

A esterilização feminina é cada vez mais utilizada como método contraceptivo, em todo o mundo, com mais de 100 milhões de procedimentos realizados. Consiste na laqueação tubária bilateral através de métodos laparoscópicos, histeroscópicos ou por laparatomia. As abordagens convencionais implicam a realização de incisões abdominais e são realizadas sob anestesia geral. As principais complicações são anestésicas, sendo raras as lesões vasculares ou de órgãos pélvicos como intestino, bexiga ou útero.

Na realidade, existe no Brasil uma cultura da esterilização, em que se acredita que a ligadura tubária é a melhor opção, se não a única, para o controle populacional das camadas de menor potencial econômico, calçados em teorias que acreditam que somente o controle populacional levaria o país ao desenvolvimento econômico. Em contrapartida, se é possível fundamentar práticas que utilizem as pessoas como meio, é possível pensar procedimentos, seja na política, seja no direito, capazes de preservarem o princípio constitucional e de direitos humanos da dignidade da pessoa.

Ao observar pelo viés do direito percebe-se o quão esse instituto que é regulamentado por lei é danoso para as mulheres, tendo em vista que, pelo fato do Estado precisar intervir e regulamentar a esterilização feminina mesmo que de forma voluntária não poder exercer seus direitos reprodutivos. O que tem mudado a função social da mulher que é mas só de procriar, cuidar e zelar pelo lar. Com o movimento feminista as mulheres desenvolveram um senso critico, que rompeu com a opressão de sua sexualidade e reprodução, instigaram a discussão à cerca das políticas controlistas e ao gerenciamento da sexualidade, que as afetam diretamente.

\section{2-O QUE É ESTERILIZAÇÃO FEMININA}

Para Maluf (2013, p. 283), “a esterilização em seres humanos pode ser entendida como qualquer intervenção da qual uma pessoa torna-se incapaz de procriar, de modo definitivo e irreversível", sem, todavia, perder a capacidade de praticar o ato sexual. As principais técnicas 
de esterilização permitidas no Brasil são a Vasectomia e Laqueadura Tubária. Neste estudo estaremos abordando a questão da esterilização feminina.

A esterilização é um método contraceptivo irreversível. A esterilização feminina tem sido utilizada indiscriminadamente como forma de controle de natalidade, no qual o médico fecha as trompas através de procedimento cirúrgico, tendo como objetivo evitar a gravidez, uma vez que impede o espermatozoide de alcançar e fertilizar o óvulo.

A sua irreversibilidade o torna um método bastante drástico e delicado, mesmo para as pessoas capazes de autodeterminação. Estudos revelam que $50 \%$ das mulheres que são esterilizadas antes dos 25 anos arrependem-se de se submeter à cirurgia (VIEIRA, 2008, p. 2).

\section{1-ESTERILIZAÇÃO VOLUNTÁRIA}

A esterilização pode ser entendida como o ato de se tornar infértil, ou seja, é a realização de cirurgia para que o homem, ou a mulher, não venham a ter filhos. Tal procedimento veio à tona com a expansão populacional dos séculos XIX e XX, e com o avanço da medicina.

A esterilização voluntária e demais métodos de regulação da fertilidade foram regulamentados pela Lei $\mathrm{n}^{\circ}$ 9.263/96, com o propósito de preencher lacunas da legislação legal e garantir ao indivíduo o exercício pleno dos seus direitos reprodutivos.

A esterilização voluntária foi regulada na década de 90, objetivando normatizar um procedimento que já acontecia sem nenhuma espécie de controle prévio, culminando em esterilizações em massa, sem nenhum parâmetro, incidindo inclusive no aumento do número de partos cesáreos para este fim.

Portanto, entende-se que a esterilização voluntária é permitida no Brasil, com as ressalvas estabelecidas no artigo 10 da Lei 9263/96 que trataremos mais à frente, quais sejam, "idade" ou "número de filhos", quer dizer, é permitida a homens e mulheres capazes, maiores de 25 anos de idade ou que, pelo menos, já tenham dois filhos vivos, observado o prazo mínimo de sessenta dias entre a manifestação da vontade e o ato cirúrgico, objetivando desencorajar a esterilização precoce.

Pode-se observar, que o legislador não apenas visou tratar do planejamento familiar, como também buscou preservar a dignidade da pessoa humana. Há de se ressaltar, casos em que a mulher cria sozinha os filhos e com muita dificuldade financeira, em um estado familiar deplorável. 
De acordo com Bottega (2007) a esterilização pode ser voluntária, quando realizada com o consentimento do esterilizado e involuntária ou compulsória, quando realizada sem a sua concordância. No que tange a sua finalidade, ela pode ser classificada como terapêutica, quando está relacionada à manutenção da saúde do indivíduo ou não terapêutica quando ocorre sem as devidas indicações médicas de saúde.

Em seu estudo Diniz (2011) classifica a esterilização humana artificial como eugênica, terapêutica, cosmetológica, por motivo econômico-social ou para a limitação da natalidade.

No Brasil só é permitida a esterilização para a limitação da natalidade desde que seja de forma voluntária e a esterilização terapêutica que é a decorrente de estado de necessidade ou legitima defesa, mas essa segunda ainda sofre limitações por lei. Trataremos nesse artigo da esterilização para fins de limitação da natalidade que é a esterilização voluntária para fins de planejamento familiar e controle da prole, a vontade não pode sofrer qualquer forma coercitiva, sob pena de se considerar vício na manifestação da vontade por coerção.

Nesse viés Diniz ressalta e corrobora com os demais estudos ao afirmar que é vedado na esterilização voluntária para fins de planejamento familiar que ela se dê por emprego de métodos que firam a dignidade humana, causando mutilação como a cirurgia ablativa das gônadas ou imputações imotivadas. Sobre a esterilização é proibido aos médicos segundo o artigo 42 do Código de Ética Médica “desrespeitar o direito do paciente de decidir livremente sobre método contraceptivo, devendo sempre esclarecê-lo sobre indicação, segurança, reversibilidade e risco de cada método".

\section{2-ESTERILIZAÇÃO COMPULSÓRIA /JUDICIAL}

Para Albuquerque (2013) a esterilização compulsória não se revela medida lícita sob a ótica do ordenamento jurídico brasileiro. Nas hipóteses em que a pessoa for absolutamente incapaz de consentir e for maior de 25 anos ou, independentemente da idade, com dois filhos vivos; ou na hipótese de risco de morte ou à saúde da mulher ou do futuro concepto, a esterilização de absolutamente incapaz pode ser autorizada pelo juiz a pedido da família ou do responsável legal, mediante processo de decisão substituta.

Tal hipótese não configura esterilização compulsória, porquanto a pessoa não é capaz de escolher pelo procedimento ou não, bem como todas as medidas tendentes ao respeito de seus desejos, valores e crenças deverão ser adotadas mediante o emprego dos modelos de decisão substituta. 
A decisão judicial que determina e não tão somente autoriza a esterilização viola o princípio da dignidade humana, uma vez que não respeita a autonomia da pessoa humana e a trata como mero objeto.

Em suma observadas as condições destacadas acima, cabe ao Estado promover o exercício a livre autonomia e não cercear esse direito. Autorizar é diferente de determinar, e essa observação é de extrema importância quando da tomada de decisões por parte do deficiente e seus familiares.

De acordo com Schulman (2018) no entendimento da ONU (Organização das Nações Unidas), é evidente que a esterilização forçada consiste em uma violação à vedação da tortura, tratamento cruel, desumano ou ainda punição degradante, como já exaltou tanto por meio da Organização Mundial da Saúde (OMS), quanto por meio do Conselho de Direitos Humanos.

Diante dessa assertiva consagra-se, desta maneira, a proteção dos direitos reprodutivos, o planejamento familiar, o direito ao corpo, a fertilidade, a definição quanto ao número de filhos e, de maneira expressa, a vedação legal à esterilização compulsória. A imposição de tratamentos, mesmo sob a alegação de que seria o interesse do paciente exige a máxima cautela.

\section{3-PRINCÍPIO DA MÍNIMA INTERVENÇÃO ESTATAL}

A partir do momento que a esterilização feminina é tratada como um problema de saúde pública, infere-se que, necessita da intervenção do estado para desenvolver essa celeuma.

É visto que o Estado Mínimo é oriundo de revoluções que pregavam o Liberalismo de tal modo que o Estado passou a interferir minimamente, ou seja, apenas na segurança onde começaram a surgir problemas e ficou claro a necessidade de também intervir na área social.

A doutrina prevê que a intervenção mínima deve garantir que os indivíduos tenham preservado em sua totalidade de forma individual e coletiva todos os seus direitos como cidadãos.

A intervenção mínima do Estado é como o nome já diz intervenção mínima, ou seja, o Estado da a "liberdade" no sentido de que o cidadão é livre para praticar seus atos, mas que essa liberdade trouxe alguns problemas, uma vez que antes o Estado cuidava apenas da segurança interna e externa, e com isso a sociedade ficou um pouco que "esquecida" todavia, 
viu-se então a necessidade de também intervir na área social, pois a burguesia passava a deter além do poder econômico os meios de produção.

A busca pelo controle da reprodução humana e do crescimento populacional é antiga e historicamente tem tornado o controle sobre o corpo feminino um de seus principais campos de disputa. É durante a crise populacional dos séculos XVI e XVII que o Estado se apropria do controle sobre os assuntos reprodutivos e começa a utilizar meios cada vez mais cruéis de controlar e castigar as sexualidades não procriativas e as tentativas de contracepção:

... a principal iniciativa do Estado com o fim de restaurar a proporção populacional desejada, foi lançar uma verdadeira guerra contra as mulheres, claramente orientada a quebrar o controle que elas haviam exercido sobre seus corpos e sua reprodução. [...] essa guerra foi travada principalmente por meio da caça às bruxas, que literalmente demonizou qualquer forma de controle de natalidade e de sexualidade não procriativa, ao mesmo tempo que acusava as mulheres de sacrificar crianças para o demônio (FEDERICI, 2017, p. 174)

Os direitos reprodutivos são construídos por princípios e normas de direitos humanos que garantem o exercício individual, livre e responsável, da sexualidade e reprodução humana. É, portanto, o direito subjetivo de toda pessoa decidir sobre o número de filhos e os intervalos entre seus nascimentos, e ter acesso aos meios necessários para o exercício livre de sua de sua autonomia reprodutiva, sem sofrer discriminação, coerção, violência ou restrição de qualquer natureza." Este conceito foi escrito pela escritora Miriam Ventura, em sua $3^{\text {a }}$ edição, a obra "Direitos Reprodutivos no Brasil".

No século passado a mulher era vista apenas como um objeto sexual. Usada para satisfazer os desejos de seu dono no caso seu marido, reprodutora de filhos, além de cuidar de todos os seus afazeres domésticos.

Com o passar dos anos com movimentos libertários e feministas que ganharam relevância após a década de 60, as mulheres conquistaram uma nova concepção sobre direitos sexuais e reprodutivos.

Na medida em que se foi consolidando o contraste entre sexo e reprodução, e depois de vários debates tornou-se mais nítido este assunto no âmbito internacional. Com isso houve um plano legislativo para cada Estado para tratar sobre os direitos sexuais e reprodutivos que cuidam da liberdade de escolha que a mulher tem de exercer livremente opções sexuais e de escolher a quantidade de filhos. 
A Constituição Federal, em seu artigo $226, \S 7^{\circ}$ e $8^{\circ}$, também trouxe em seu texto os direitos sexuais e reprodutivos, que o referido diploma descreve como o "planejamento familiar". Mesmo de uma forma desorganizada, o Estado tem o dever de franquear recursos, tanto educacionais, como de saúde para garantir o seu resultado, além de promover a orientação geral sobre tais direitos, proporcionando assim a proteção individual aos membros da família.

Para esse fim, o legislador infraconstitucional elaborou duas leis de grande relevância: a Lei $n^{\circ}$ 9.263/96 de planejamento reprodutivo e a Lei ${ }^{\circ} 11.340 / 2006$ de proteção à mulher no ambiente doméstico e familiar.

Referente a esse assunto, os diplomas internacionais, são extremamente importantes e estão diretamente ligados ao assunto de planejamento reprodutivo nos dias de hoje. Além de avaliar a preocupação do Estado em relação ao uso dos métodos contraceptivos irreversíveis. No Teerã, em 1968, for realizada uma Conferência Mundial de Direitos Humanos, onde foi abordado o tema sobre os direitos sexuais e reprodutivos, no plano internacional. A norma inaugural abordada foi o artigo 16, que diz: "Os pais têm o Direito Humano fundamental de determinar livremente o número de seus filhos e os intervalos entre seus nascimentos." E posteriormente, outros documentos foram editados, dos quais apontam os seguintes:

I - Convenção sobre Discriminação contra a Mulher, de 1979 (ratificada pelo Brasil em 01.02.1984 e promulgada pelo Decreto 4.377, de 13.09.2002), a qual ordena aos Estados signatários a adoção de medidas apropriadas para assegurar a informação e o assessoramento sobre o planejamento da família (artigo 10, h) e, inclusive, o acesso a serviços médicos relativos ao planejamento familiar (artigo 12, 1);

II - Convenção sobre Direitos da Criança, de 1989 (ratificada pelo Brasil em 24.09.1990 e promulgada pelo Decreto 99.710, de 21.11.1990) que versa sobre o direito à saúde, com vistas ao desenvolvimento da assistência médica preventiva e dos serviços de planejamento familiar (artigo 24, 2, f);

III - Conferência das Nações Unidas sobre população e desenvolvimento, de 1994, realizada no Cairo, a qual prevê que os Estados devem tomar medidas apropriadas para assegurar o acesso universal e igualitário aos serviços de saúde, relativos à reprodução e à sexualidade - sem nenhum recurso à coerção - determinando-se o direito fundamental de decidir livre e responsavelmente acerca do número de filhos e o espaço entre os nascimentos; assim como a disposição de informação, educação e meios para exercício dos referidos direitos (princípio 8).

IV - Quarta Conferência Mundial sobre a Mulher, de 1995, sediada em Pequim, que buscou implementar o conceito de família democrática, ao promover a igualdade de direitos entre homens e mulheres no âmbito familiar, no que tange ao acesso aos recursos, às oportunidades, à partilha 
das responsabilidades familiares, cuja aplicação, em última análise, fortalece a democracia ( princípio 15).

Cabe ressaltar o avanço encampado por esta conferência no que concerne aos direitos fundamentais da mulher. A análise sobre a mulher como objeto, que precisava ser regulada em sua sexualidade para efeitos de controle demográfico, passou a ser outra qual seja, a de sujeito de direitos sexuais e reprodutivos, de modo que a mulher conquistou maior autonomia em relação ao uso do seu próprio corpo.

Visto que, esta conferência, em seu princípio 96, reforçou a ideia de que a mulher possui domínio sobre sua própria sexualidade e tem o dever de tomar suas decisões livremente. Mais importante, ressaltou-se a igualdade de gêneros no que se refere à sexualidade e à procriação, que implica num respeito total da integridade da pessoa, exigindose, para consecução deste fim, "o respeito mútuo, o consentimento e a partilha da responsabilidade dos comportamentos sexuais e de suas consequências".

O conceito de planejamento reprodutivo já sofreu várias críticas por parte da sociedade, pois esse tema envolve também os direitos desde o nascedouro e foi entendido como uma intromissão na liberdade familiar. Ademais, cabe ressaltar que nas legislações anteriores, constituições brasileiras de 1934, 1936 e 1946, esse tema mostrou-se limitado, pois se restringiu a assistir famílias com grande quantidade de membros.

O Estado, hoje, nesse tema, atua como colaborador do cidadão, oferecendo condições para que ele possa decidir o futuro de sua família.

Essa atuação é tida como uma intervenção mínima do Estado no âmbito do Direito de Família constitucionalizado, que é dividida em positiva e negativa. A atuação positiva se afirma na disponibilização aos cidadãos de informações e métodos contraceptivos lícitos e conceptivos. Na atuação negativa, abstém-se de qualquer interferência no processo decisório dos homens e mulheres, pois a escolha dos indivíduos deve ser livre de qualquer forma de estimulo ou desestimulo estatal.

Após a promulgação da lei de planejamento reprodutivo houve um crescente interesse estatístico pelo Estado no tema relacionado à esterilização, ao contrário de antes, que havia poucos dados.

A regulamentação da prática de esterilização nos serviços de saúde pública proporcionou uma homogeneização do acesso à esterilização feminina nos diferentes níveis sociais e maior participação do homem na contracepção de mulheres com melhor nível 
socioeconômico. Contudo, houve pouco avanço na contracepção de mulheres com nível socioeconômico baixo.

No nosso país, ainda falta um maior divulgação à população sobre o planejamento reprodutivo, em especial à saúde sexual e reprodutiva. O planejamento reprodutivo, embora verse sobre a intimidade e seja de responsabilidade do indivíduo, é um direito fundamental inerente à Saúde e à esfera social, de modo que compete à Defensoria Pública a promoção e a orientação da população sobre os seus respectivos direitos sexuais e reprodutivos, conforme preceitua a própria Constituição Federal em seu artigo 134.

\section{4-ASPECTOS CONSTITUCIONAIS}

No que tange a visão constitucional a laqueadura no Capítulo VIII, "Da família, da criança, do adolescente, do jovem e do idoso", em seu art. 226, parágrafo $7^{\circ}$, lê-se:

Fundado nos princípios da dignidade da pessoa humana e da paternidade responsável, o planejamento familiar é livre decisão do casal, competindo ao Estado propiciar recursos educacionais e científicos para o exercício desse direito, vedada qualquer forma coercitiva por parte de instituições oficiais ou privadas.

A Constituição Federal de 1988 reconheceu, no seu art. 226, $\S 7^{\circ}$, o direito ao livre planejamento familiar, que é o direito que cada indivíduo tem de decidir livremente se desejar procriar ou não, e planejar o momento em que desejam ter filhos, o espaçamento entre eles e, ainda, de escolher quais métodos contraceptivos deseja utilizar como meio de controle de fecundidade. Em síntese, é a garantia ao direito à procriação em seus aspectos positivos e negativos, devendo o seu exercício estar pautado no ideal de paternidade responsável e dignidade da pessoa humana.

Com o intuito de regulamentar a disposição constante da $\mathrm{CF} / 88$, foi promulgada a Lei de Planejamento Familiar, no 9.263 de 1996, que, buscando dar providências e regular o exercício do direito em comento, previu que cabe ao Estado propiciar todos os métodos de concepção e contracepção, através de medidas educativas, preventivas e garantia de acesso à informação e métodos contraceptivos, possibilitando que o homem e a mulher, livremente, planejem e organizem sua estrutura familiar.

Cabe ressaltar que a atenção estatal não deve voltar-se, tão somente, àqueles que não querem ter filhos, mas também para a procriação, devendo facilitar a formação da família. Nessa linha, a lei $n^{\circ} 9.263 / 96$ passou a permitir a realização do procedimento cirúrgico de 
esterilização voluntária - que antes era tipificado pelo Código Penal como crise de lesão corporal grave por perda ou inutilização de membro, como método contraceptivo - que em síntese, é ato de se tornar estéril, isto é, impossibilitado de procriar.

A partir desse momento, então, o Estado brasileiro passou, definitivamente, a aceitar a diferenciação entre os direitos sexuais e reprodutivos, haja vista que, ao preceituar o livre acesso à métodos contraceptivos e a possibilidade de escolher ter filhos ou não, reconheceu que os indivíduos podem exercer sua sexualidade e possuir autonomia sobre o uso do próprio corpo sem, necessariamente, procriar.

Em síntese, o ato sexual e a sexualidade não estavam mais condicionados à procriação, e, havendo a aceitação da esterilização como método de planejamento familiar do casal, consolidou-se a ideia de que a família deixou de ter fins de reprodução, mas de promoção da dignidade e felicidade do homem.

Cumpre esclarecer, todavia, que o exercício do direito a se esterilizar não foi admitido indiscriminadamente, à medida que a lei de planejamento familiar estabeleceu uma serie de critérios objetivos para a sua realização, dentre eles, o mais polêmico, o consentimento expresso do cônjuge, sendo que a execução sem o preenchimento dos requisitos consiste em crime, com pena de até oito anos de reclusão.

A lei $n^{\circ} 9.263 / 96$, portanto, regulamenta a esterilização cirúrgica e estabelece que é dever do Estado prover informações e disponibilizar outros métodos anticoncepcionais, esclarecendo as dúvidas sobre o método definitivo, para garantir a liberdade de escolha dos cidadãos. As mulheres que procuram prevenção contraceptiva através do Sistema Único de Saúde (SUS) podem optar por métodos temporários/reversíveis que incluem métodos de barreira e métodos hormonais por diferentes vias de administração; ou pelo método definitivo, através da esterilização voluntária feminina por meio de ligadura tubária (BRASIL, 2016)

Percebe-se que, ainda que a esterilização voluntária cirúrgica seja permitida por lei, o que é um avanço, o condicionamento da sua prática à preenchimento de critérios, como ser maior de 25 (vinte e cinco) anos, possuir dois filhos vivos, autorização judicial em caso de pessoas incapazes ou não casadas, expresso consentimento do cônjuge, fere os mais diversos direitos constitucionalmente protegidos como a dignidade da pessoa humana, autonomia privada, liberdade, e, principalmente, o livre planejamento familiar de cada sujeito (e não apenas do casal) e a possibilidade de dispor de forma livre do seu corpo para satisfazer seus próprios fins. 
Pode-se observar que uma lei que deveria vir no sentido de regulamentar a Constituição Federal encontra-se em confronto com ela, em diversos momentos. O primeiro aspecto inconstitucional presente na norma refere-se à previsão da idade mínima ou de no mínimo dois filhos vivos para realizar a chamada esterilização voluntária, que está expresso em seu art. 10:

Art. 10. Somente é permitida a esterilização voluntária nas seguintes situações:

I - em homens e mulheres com capacidade civil plena e maiores de vinte e cinco anos de idade ou, pelo menos, com dois filhos vivos, desde que observado o prazo mínimo de sessenta dias entre a manifestação da vontade e o ato cirúrgico, período no qual será propiciado à pessoa interessada acesso a serviço de regulação da fecundidade, incluindo aconselhamento por equipe multidisciplinar, visando desencorajar a esterilização precoce;

É nítido que existe uma afronta à Constituição Federal de forma direta ao parágrafo $7^{\circ}$. do art. 226. Enquanto que no referido parágrafo está descrito que se trata de livre decisão do casal, mas se esse casal, for menor de 25 anos e não tiver dois filhos vivos? Ou seja, nesse momento, é necessário que o casal tenha feito a escolha de ter filhos, ou de ter dois filhos, e eles ainda têm que estar vivos para poderem exercer o direito constitucional? É isso o que a norma constitucional nos traz?

A inconstitucionalidade é flagrante nesse caso pois se o planejamento é livre, como é que podemos optar por esse planejamento somente se tiver dois filhos vivos?

Onde está a garantia constitucional de planejar não ter filhos ou ter apenas um? E ainda, se os filhos tiverem falecido? Assim, o planejamento familiar previsto na Constituição Federal não é respeitado pela norma infraconstitucional, sendo portanto esta inconstitucional. Outro ponto que ofende o nosso ordenamento jurídico encontra-se no período para "pensar" se é isso realmente que a pessoa deseja. Isso significa que não estamos respeitando a sua autonomia da vontade, pois quando uma pessoa chega para o médico com esse objetivo é porque já pensou sobre isso. Porque caberia ao Estado intervir nesse ponto? Novamente nos deparamos com a ofensa à liberdade do planejamento familiar amparado pela Constituição Federal.

Assim, o prazo para refletir sobre o tema ofende a liberdade da pessoa que quer realizar o procedimento, ofendendo assim o livre planejamento familiar. Ou seja, depois que a pessoa já decidiu é que ela deverá refletir sobre a decisão que já tomou? A oferta de acompanhamento pelo Estado durante esse período de reflexão é totalmente invasivo, eis que 
a pessoa já decidiu sobre a sua vida. Essa oferta teria que ser feita antes, quando a pessoa inicia a sua vida sexual e não quando ela já se encontra determinada a fazer a esterilização.

Outra inconstitucionalidade do referido artigo não se encontra apenas no inciso primeiro, encontramos isso nos parágrafos que lhe seguem, especialmente no parágrafo $5^{\circ}$. “§5 $5^{\circ} \mathrm{Na}$ vigência de sociedade conjugal, a esterilização depende do consentimento expresso de ambos os cônjuges."

Neste parágrafo, pode-se notar a ofensa ao princípio da dignidade da pessoa humana, a liberdade de pensamento e também a disposição do próprio corpo demonstram a inconstitucionalidade existente.

Ou seja, diante de um casamento faz-se necessário que os dois assinem consentido que um faça a esterilização voluntária. Ou seja, um do cônjuge passa a ter o direito sobre o corpo do outro nesse momento.

Por que o cônjuge tem que consentir se o casamento não tem a função principal a reprodução? Por que um cônjuge tem o direito sobre o corpo do outro, se realiza ou não a cirurgia?

No caso deste parágrafo $5^{\circ}$. da Lei do Planejamento Familiar, foi ajuizada uma ação direita de inconstitucionalidade - ADI 5097, tendo sido protocolada no ano de 2014.

A qual compreende-se ser procedente, por ser inconstitucional a exigência do consentimento do cônjuge como limitação jurídica que obsta a esterilização voluntária? pode-se concluir que a hipótese inicial aduzida para este questionamento é verdadeira. $\mathrm{Na}$ medida em que o Estado impõe esta exigência de consentimento e criminaliza a conduta quando da realização do procedimento sem a observância do requisito, legitima norma de ordem inconstitucional, a qual não é válida para produzir efeitos. A previsão colide com o art. 226 da Constituição Federal, bem como afronta o direitos à liberdade e disponibilidade física do corpo (ou autonomia ao próprio corpo), culminando com a violação do princípio da dignidade humana, princípio-luz norteador do ordenamento jurídico pátrio.

\section{5-VIOLAÇÃO DO PRINCÍPIO DA DIGNIDADE DE PESSOA HUMANA}

A dignidade humana é inviolável. Respeitá-la e protegê-la é obrigação de todos os Poderes estatais". No âmbito do constitucionalismo brasileiro, o princípio foi inserido expressamente no art. $1^{\circ}$, inciso III, da Constituição do Brasil, como fundamento da República 
Federativa e do Estado Democrático de Direito em que ela se constitui. E embora já ao tempo das Constituições de 1934, 1946 e 1967 haja referências à dignidade da pessoa, ainda que em outro contexto, a fórmula adotada pela Constituição de 1988 é não somente inovadora, como também nos remete a várias questões de ordem teórica e prática.

A dignidade da pessoa humana não é uma criação constitucional, mas um dado preexistente a toda experiência especulativa que, em face de sua relevância e conteúdo filosófico, foi constitucionalizado como fundamento da República Federativa do Brasil, a qual se constitui em Estado Democrático de Direito1. Muitos foram os autores, no âmbito do pensamento ocidental, que direta ou indiretamente trataram do tema, alguns com maior relevância, outros nem tanto. Algumas contribuições, como as de Tomás de Aquino e Kant, até hoje são consideradas referência obrigatória no estudo do tema.

$\mathrm{Na}$ verdade, a Constituição brasileira transformou a dignidade da pessoa humana em valor supremo do Estado brasileiro e, em especial, do sistema jurídico-constitucional. No constitucionalismo brasileiro contemporâneo, o homem é concebido como centro do universo jurídico-constitucional e como prioridade justificante do Direito. Esta noção nos conduz a abordar quais as consequências que esta proeminência axiológica tem para a interpretação e aplicação do texto constitucional.

Da mesma forma, questões outras como a da relação existente entre os direitos fundamentais e a dignidade da pessoa humana, e o papel que a dignidade da pessoa humana desempenha no que tange aos novos direitos que estão surgindo merecem ser analisadas. Por outro lado, a expressa inclusão da dignidade da pessoa humana na fórmula política do Estado brasileiro, como fundamento da República e do Estado Democrático de Direito, nos remete também à questão da legitimidade do poder estatal e da interpretação constitucional num Estado que se propõe democrático e pluralista.

Apesar de sua relevância histórico-cultural, dos múltiplos enfoques em que se poderia abordar a dignidade da pessoa humana e da magnitude de tais considerações, lamentavelmente, na prática, o princípio não alcançou o grau de normalidade que lhe é concedido pelo sistema constitucional. E muito contribui para esta fraca normatividade a recusa em se atribuir a categoria de normas aos princípios, principalmente quando dotados de forte conteúdo axiológico, tal qual o da dignidade da pessoa humana. Não obstante, verificase que, no âmbito da doutrina constitucional contemporânea, se observa um esforço no 
sentido atribuir aos princípios um papel compatível com sua importância, reconhecendo que também os princípios, juntamente com regras, podem ser fontes de solução jurídica.

Nesse viés de pensamento, a doutrina nacional tem produzido, principalmente nos últimos anos, ampla contribuição acadêmica ao debate sobre o papel reservado ao princípio fundamental da dignidade da pessoa humana no constitucionalismo brasileiro. Todavia, certamente o debate não está esgotado. Muito ainda há por fazer. Prova disto, por exemplo, é que a polissemia que o conceito de dignidade humana encerra em si mesmo nos leva a problemas com o reconhecimento de seu âmbito de proteção. Em função de seu forte conteúdo valorativo a exata conceituação do princípio da dignidade da pessoa humana apresenta-se eivada de dificuldades, o que muitas vezes dá margem a conceituações desvinculadas de seu real significado histórico-cultural.

Alguns exemplos em relação a direitos fundamentais que se apoiam no princípio da Dignidade da pessoa humana são o direito à vida, o direito a uma morte digna, a liberdade, a igualdade, a segurança, a propriedade, entre vários outros previstos no Art. $5^{\circ}$ da Constituição Federal. Portanto, é consensual que não se pode praticar atos jurídicos que não estejam sob o respaldado deste título tão importante para a base do Estado Democrático de Direito no Brasil.

Em seu estudo Barroso (2012) conceitua o princípio da dignidade da pessoa humana adotado baseado no pensamento de Immanuel Kant, segundo o qual o ser humano é dotado de um conjunto de características comuns, como razão, sentimentos e capacidade de comunicação. Essas características conferem à espécie humana um "status especial e superior no mundo, distinto do de outras espécies", ou valor intrínseco. Significa que o ser humano é um fim em si mesmo, ao invés de um meio para fins individuais ou coletivos de outrem. Essa noção coincide com a concretizada pelo Supremo Tribunal Federal, no julgamento da ADPF 54, no sentido de que é "inumano e impensável tratar a mulher como mero instrumento para atender a certa finalidade".

Alguns exemplos em relação a direitos fundamentais que se apoiam no princípio da Dignidade da pessoa humana são o direito à vida, o direito a uma morte digna, a liberdade, a igualdade, a segurança, a propriedade, entre vários outros previstos no Art. $5^{\circ}$ da Constituição Federal. Portanto, é consensual que não se pode praticar atos jurídicos que não estejam sob o respaldado deste título tão importante para a base do Estado Democrático de Direito no Brasil.

E para que o respeito à dignidade humana possa ser um autêntico lugar da ética, devese contemplar os seguintes pressupostos fundamentais: a) o ser humano é um fim para si 
mesmo e não pode ser reduzido a meio; b) o homem reclama um respeito incondicional e absoluto; c) a pessoa é a protocategoria do universo ético e, enquanto tal é origem e meta de todo empenho moral. (MARTINI, 2011).

\section{6-ASPECTOS BIOÉTICOS}

A bioética é a ética aplicada à vida e, abrange temas que vão desde uma simples relação interpessoal até fatores que interferem na sobrevivência do próprio planeta. Dentro da medicina, este termo está intimamente ligado à noção de bem-estar. Faz-se relevante dizer que o conceito de bioética que temos hoje vem sendo construído desde a década de 60, época em que marcantes avanços científicos ocorreram, dentre eles o primeiro transplante de coração. Entretanto, a palavra "bioética" surgiu apenas no ano de 1971, na obra de Van Rensselaer Potter intitulada de Bioethics: bridge to the future. A partir daí, esta palavra tornou-se cada vez mais presente e significante, sobretudo nas décadas de 80 e 90, período em que realiza-se de forma concreta o chamado "projeto genoma humano", trabalho biológico e tecnológico responsável pelo total mapeamento genético do ser humano, e com claras intensões de complementar e/ou criar novos estudos a respeito da terapia gênica.

Para Cordeiro (1998, p.02) as principais razões para o surgimento da bioética foram

a) Abusos na utilização de animais e seres humanos em experimentos;

b) Surgimento acelerado de novas técnicas desumanizantes que apresentam questões inéditas, como por exemplo, clonagem de seres humanos;

c) Percepção da insuficiência dos referenciais éticos tradicionais, pois devido ao rápido progresso científico, torna-se fácil constatar que os códigos de ética ligados a diferentes profissões não acompanharam o rápido progresso científico, sendo diversas vezes insuficientes para julgar os temas polêmicos da bioética.

O que é preciso compreender a respeito da criação da bioética, para que se possa assimilar a sua importância junto ao biodireito, é que o emprego de descobertas científicas pode, muitas vezes, afetar negativamente a sociedade ou até mesmo o planeta. Assim sendo, a análise das vantagens e desvantagens do emprego de uma determinada tecnologia ou da realização de certos experimentos, deve ser avaliada com bastante cautela e da forma mais profissional possível. Contando para isso com a participação de comitês formados por indivíduos de diversas áreas de conhecimento, sendo: Ciências tecnológicas (medicina, veterinária e biologia); Ciências Humanas (filosofia, teologia, psicologia e antropologia); 
Ciências sociais (economia e sociologia); Ciências Políticas e o Direito as principais parceiras desta construção.

Ainda a respeito sobre como a bioética se organiza, segue a descrição de seus princípios segundo os apontamentos de Loch (2002, p. 22)

a - Autonomia ou princípio da liberdade: se baseia no fato de que na relação médico-paciente, este último possui o direito de ser informado sobre seu estado de saúde, detalhes do tratamento a ser prescrito e tem toda a liberdade de decidir se irá ou não se submeter ao tratamento determinado e caso o paciente não possa decidir, os pais ou responsáveis é que tomam a decisão. Em casos de experimentos conduzidos com seres humanos, os indivíduos submetidos aos testes devem receber detalhes dos procedimentos a serem adotados e dar uma autorização, por escrito, de que deseja participar da pesquisa. Na medicina veterinária, como o animal não pode tomar essa decisão, cabe ao médico veterinário fornecer todas as informações sobre $o$ animal e possíveis tratamentos e obter a autorização do proprietário para a realização dos procedimentos.

b - Beneficência ou princípio da não-maleficência: toda e qualquer tecnologia deve trazer benefícios para a sociedade e jamais causar-lhe malefícios. É fato nos dias de hoje, que a bioética está mais relacionada aos seres humanos do que aos animais, pois a maior parte dos experimentos existentes visa beneficiar o homem e não os animais.

c - Justiça distributiva: os avanços técnico-científicos devem beneficiar a sociedade como um todo e não apenas alguns grupos privilegiados. Por fim, é preciso saber que a bioética também divide-se em dimensões, extensões conhecidas como 'grandes áreas de estudo da bioética. São estas dimensões:

d - Dimensão pessoal: estuda a relação entre os profissionais responsáveis e seus pacientes. A liberdade do indivíduo ou responsável pelo indivíduo deve ser respeitada;

e - Dimensão social, econômica e política: tem como objetivo estabelecer critérios para que seja determinada a alocação e distribuição de recursos, bem como tentar reduzir as diferenças econômicas e sociais dentro de um país ou entre países. Dentre os diferentes assuntos que são abordados nessa área da bioética, destacam-se: alocação de recursos financeiros; patentes; desequilíbrio entre países ricos e pobres e fome;

$\mathrm{f}$ - Dimensões ecológicas: os principais temas que fazem parte da pauta de discussão da bioética no campo da ecologia são proteção ao meio ambiente, exploração dos recursos naturais, desertificação, poluição, extinção de espécies, equilíbrio ecológico, utilização de animais e plantas em condições éticas, proteção da qualidade de vida dos animais, desequilíbrio entre países ricos e pobres, problemas nucleares e proteção da biodiversidade;

g - Dimensão pedagógica: trata-se da discussão de alternativas que visem uma melhora no ensino e aprendizagem nas instituições;

h - Dimensões biológicas ou bioética especial: dentro deste grupo da bioética, destacamos o começo da vida, o diagnóstico pré-natal, o aborto provocado, a reanimação do recém-nascido, a engenharia genética e organismos geneticamente modificados, terapia gênica, eugenia, reprodução medicamental assistida, clonagem, transplante de órgãos, experimentação animal e em humanos, eutanásia e distanásia. 
A importância das discussões a respeito da bioética, sobretudo, a luz do Direito é fazer com que a ciência não utilize indiscriminadamente as novas tecnologias logo que se tornem viáveis, mas somente apenas após possuir o conhecimento e a sabedoria suficientes para utilizá-las em benefício da humanidade e não em seu detrimento. Nesse sentido, a bioética permitirá que a sociedade decida sobre as tecnologias que lhe convêm.

Antes de tudo é preciso dizer que o biodireito está intimamente relacionado aos mais variados conceitos de ética e socialização que o ser humano pode conhecer e praticar e, por isso, acredita-se que este é um tema de suma importância para os discentes e profissionais do Direito, ocasião que este assunto tão atual e complexo, também se apresenta como um objeto de estudo capaz de abranger e aprofundar bastante o conhecimento pessoal e legislativo daqueles que se dispõem a lidar com as inúmeras questões que advêm das relações entre as leis e as práticas humanas, como é o caso da advocacia.

Pois bem, a constante evolução pela qual a medicina tem passado na últimas décadas e o quanto estas mudanças têm trazido à humanidade a ideia do quanto a Biotecnologia é (e ainda) será capaz. E, como consequência disso, vários têm sido os questionamentos nos campos ético e jurídico acerca de temas antes inimagináveis, como a clonagem de seres humanos para o transplante de órgãos ou o congelamento de corpos para um possível retorno 'a vida'. Deste modo, e com o dinamismo com que surgem e são adquiridos tais conhecimentos, surge a necessidade de normas reguladoras para que procedimentos utilizados pela ciência atinjam seus objetivos sem ferir os princípios éticos consolidados e/ou direitos humanos fundamentais anteriormente conquistados, tais quais o direito a dignidade do ser humano e o direito à vida as inúmeras questões que advêm das relações entre as leis e as práticas humanas, como é o caso da advocacia.

Pois bem, a constante evolução pela qual a medicina tem passado na últimas décadas e o quanto estas mudanças têm trazido à humanidade a ideia do quanto a Biotecnologia é (e ainda) será capaz. E, como consequência disso, vários têm sido os questionamentos nos campos ético e jurídico acerca de temas antes inimagináveis, como a clonagem de seres humanos para o transplante de órgãos ou o congelamento de corpos para um possível retorno 'a vida'. Deste modo, e com o dinamismo com que surgem e são adquiridos tais conhecimentos, surge a necessidade de normas reguladoras para que procedimentos utilizados pela ciência atinjam seus objetivos sem ferir os princípios éticos consolidados e/ou direitos 
humanos fundamentais anteriormente conquistados, tais quais o direito a dignidade do ser humano e o direito à vida.

\section{7-CONSIDERAÇOES FINAIS}

Pode-se inferir eu no contexto atual a esterilização voluntária feminina é um direito constitucional brasileiro, o qual é regulamentado pela Lei 9263/96 conhecida por Lei do Planejamento Familiar. Na esfera internacional, é tido como um direito humano de todos os cidadãos que buscam seu planejamento familiar. Inserida no rol dos direitos reprodutivos, possui todas as garantias legais para uma efetiva escolha consciente, dentre os demais métodos contraceptivos. Nesta concepção, é de competência do Estado a promoção de meios que possibilitem o exercício do planejamento familiar. Para tanto foi criada a inovadora Lei do Planejamento Familiar que acompanhou todo o atual entendimento sobre direitos reprodutivos.

Infere-se que não se pode ter o planejamento familiar controlado. Cada um tem o dever e o direito de gerar outro ser. Em suma, se deseja não mais procriar, deve ser orientado e informado das consequências de seu ato. A laqueadura compulsória é uma hipótese rara na qual a mulher é compelida a passar por esse procedimento, que é claro e evidente que fere alguns princípios com a omissão de alguns procedimentos, os quais são assegurados a quaisquer que sejam todos os meios de defesa.

Diante da incontestável realidade é preciso também reafirmar que o conceito de dignidade humana não admite regalias nem desigualdades, porque é um a priori a ética pertence a todos os seres humanos. Logo, a dignidade da pessoa humana como categoria moral demonstra certa primazia por aqueles cuja dignidade humana foi/é maltratada ou diminuída.

Desse modo, afirma-se que a sociedade só pode auto denominar-se plena, quando conseguir representar os anseios de todos os seus cidadãos, respeitando os direitos fundamentais completamente, dentre eles, o direito de se ter uma vida digna. A dignidade da pessoa não é somente o fundamento dos direitos humanos, mas é em si mesma o direito mais importante de todos. A bioética como ponderação recente, ainda tem muito a crescer e, consequentemente, o biodireito tem muito a lhe fornecer, abarcando suas ideias e construindo, através das leis, um caminho concreto e aplicável para a sociedade. 


\section{8-REFERÊNCIAS}

ALBUQUERQUE, Aline. Esterilização compulsória de pessoa com deficiência intelectual: análise sob a ótica do princípio da dignidade da pessoa humana e do respeito à autonomia do paciente. 2013. Disponível em: htp://www.saocamilosp.br/pdf/bioethikos/99/a2.pdf. Acesso em: 16 MAR 2019.

AWAD, Fahd. O princípio constitucional da dignidade da pessoa humana. Revista Justiça do Direito, v. 21, n. 1, 2012.

BOTTEGA, Clarissa. Liberdade de não procriar e esterilização humana. 2007. Disponível em: http://revistaemam.kinghost.net/revista/index.php/rjunic/article/view/324/294. Acesso em: 20 MAR 2019.

BRASIL. Constituição, 1988. Constituição Federativa do Brasil. Brasília: Senado Federal, 1988.

BRASIL. Lei no 9.263, de 12 de janeiro de 1996. Brasília, 15 jan 1996. Seção 1, p.1-3. Disponível em: http://www.planalto.gov.br/ccivil_03/leis/L9263.html Acesso em: 01 mar. 2019.

BRAUNER, Maria Cláudia Crespo. Direito, sexualidade e reprodução humana: conquistas médicas e o debate bioético. Rio de Janeiro: Renovar, 2003.

DINIZ, Maria Helena. O Estado atual do biodireito. 8 ed. São Paulo: Saraiva, 2011.

FRANCO JUNIOR, Raul de Mello. Planejamento familiar, esterilização e responsabilidades da classe médica. Revista UNIARA, Araraquara-SP, v. 7, 2000.

FEDERICI, Silvia. Calibã e a bruxa: mulheres, corpo e acumulação primitiva. Tradução: coletivo Sycorax. São Paulo: Elefante, 2017.

GRECO, Rogério. Curso de Direito Penal. 13ª edição, Editora Impetus, 2011.

LOCK, Jussara de Azambuja. Princípios de Beneficência e Não-Maleficência. In: Costa SIF, Iniciação à Bioética. Brasília: Conselho Federal de Medicina, 2002.

MALUF, Adriana Caldas do Rego Freitas Dabus. Curso de bioética e biodireito. 2. ed. São Paulo: Atlas, 2013.

MARTINI, Andrea. Dignidade da Pessoa Humana - Princípio Constitucional Fundamental. $6^{\mathrm{a} e d . ~ C u r i t i b a: ~ J u r u a ́, ~} 2011$. 
RIVABEM, Fernanda Schaefer. A dignidade da pessoa humana como valor-fonte do sistema constitucional brasileiro. Revista da Faculdade de Direito UFPR, v. 43, 2008.

SARLET, Ingo Wolfgang. Dignidade da Pessoa Humana e Direitos Fundamentais na Constituição Federal de 1988. $8^{\text {a }}$ ed. Porto Alegre: Livraria do Advogado, 2010.

SARMENTO, Daniel. Os princípios constitucionais da liberdade e da autonomia privada, in Dos Princípios Constitucionais: Considerações em torno das normas principiológicas da Constituição, São Paulo, Malheiros, 2003.

SCHULMAN, Gabriel. Esterilização Forçada, Incapacidade Civil e o Caso Janaína: "não é segurando nas asas que se ajuda um pássaro a voar". 2018. Revista Eletrônica Direito e Sociedade. Canoas, v. 6, n. 2, 2018. Disponível em:

https://revistas.unilasalle.edu.br/index.php/redes/article/view/4952. Acesso em 21 MAR 2019.

YAMAMOTO, Sergio Toshio. A esterilização cirúrgica feminina no Brasil, controvérsias na interpretação e desafios na aplicação da Lei 9263. 2011. Tese de Doutorado.

Universidade de São Paulo. 